\title{
Predicting Aesthetic Preferences: Does the Big-Five Matters?
}

\author{
Carolyn Salimun ${ }^{1}$, Esmadi Abu bin Abu Seman², Wan \\ Nooraishya binti Wan Ahmad ${ }^{3}$, Zaidatol Haslinda binti \\ Abdullah Sani ${ }^{4}$ \\ Faculty of Computing and Informatics \\ Universiti Malaysia Sabah, Jalan Sungai Pagar \\ 87000 F.T. Labuan, Malaysia
}

\author{
Saman Shishehchi ${ }^{5}$ \\ Imam Khomeini International University \\ Buin Zahra Higher Education Center of Engineering and \\ Technology, Buin Zahra, Qazvin \\ 3451745346, Iran
}

\begin{abstract}
User experience is imperative for the success of interactive products. User experience is notably affected by user preferences; the higher the preference, the better the user experience. The way users develop their preferences are closely related to personality traits. However, there is a void in understanding the association between personality traits and aesthetic dimensions that may potentially explain how users develop their preferences. This paper examines the relationship between the Big-Five personality traits (Openness to Experience, Conscientiousness, Extraversion, Agreeableness, and Neuroticism) and the two dimensions of aesthetics (classical aesthetics, expressive aesthetics). Two hundred twenty participants completed the Big-Five questionnaire and rated their preference for each of the ten images of web pages on a 7point Likert scale. Results show Openness to Experience, Conscientiousness, Extraversion, and Neuroticism were not significantly correlated with aesthetic dimensions. Only Agreeableness showed a significant correlation (although weakly) with both classical and expressive aesthetics. The finding conforms to literature that personality traits have influence on the preference of individual design features in lieu of aesthetic dimensions. In other words, personality traits are inapt predictor of aesthetic dimension. Therefore, more studies are needed to explore other factors that potentially help to predict aesthetic dimensions.
\end{abstract}

Keywords-User experience; aesthetic dimensions; personality traits; big-five

\section{INTRODUCTION}

User preferences play a significant role in improving the quality of user experience; the higher the preference, the better the user experience [1][2][3]. Many factors can influence user preferences, and among the most important factors is interface aesthetics [4][5][6]. The author in [7] suggested in their influential work on the dimensionality of aesthetics that aesthetics in interface design consisted of two dimensions: classical aesthetics and expressive aesthetics. Classical aesthetics emphasise clarity, orderly, symmetrical and clean design and is closely related to many of the design rules advocated by usability experts. Conversely, expressive aesthetics accentuate creativity, originality, exquisiteness, and the ability to go against design conventions. The aesthetic dimensions of classical and expressive aesthetics have been discussed thoroughly in the literature. However, little is known about which of these two aesthetic dimensions highly correspond with user preferences.

According to [8][9][10][11], user preference is influenced by overall aesthetics during the initiation stage and followed by individual design features on the latter. Wood and Keller [11] explained that preference is the result of how the visual system organises and groups the incoming information. This conclusion corroborates [9]'s finding, where only 50 milliseconds are required to react to overall aesthetics. This spontaneous reaction time was found to be consistent throughout the system utilisation by [10], who studied the consistency of immediate aesthetic perceptions. Furthermore, [8]'s work on web usability using eye-tracking concludes that users looked at the overall design first, followed by specific design features afterwards. Therefore, aesthetics is arguably the by-product of the overall design effect rather than the details comprising it.

Despite the notion that aesthetics is a result of the overall design, several works report that aesthetic preferences are closely related to personality traits through the users' mental model [12]. The mental model explains how users simplify the complexity and details of external reality into a proportional representation applicable for decision making. This process of representation reduces individual details to fewer relevant entities with relationships between them, useful for decision making at hand. Since personality is integrated within the mental model, personality traits are likely to affect users' preferences.

User preferences over interface design can at some point be predicted by personality traits, where certain personality traits trigger preferences for specific design features (e.g. buttons, font, icons, information density, menu structure, navigation, theme, etc.) [13][14][15][16][17][18][19][20]. Personality traits as classified by the big-five also known as Five-Factor Inventory (FFI), categorised human characteristic patterns into five broad dimensions, represented by the acronym OCEAN or CANOE: Openness to Experience (O) or sometimes abbreviated as Openness, Conscientiousness (C), Extraversion (E), Agreeableness (A), and Neuroticism (N) [21]. Openness to experience is defined as the tendency to actively seek and appreciate new experiences and tolerate novel situations. This personality trait is manifested by curiosity, imagination, and being untraditional [22][23][24]. 
Conscientiousness is defined as the tendency to be cautious, consistent, and organised; manifested by self-regulation and adherence to norms [25] [26][27]. Extraversion is defined as the tendency to be extrovert, manifested by assertiveness, talkativeness, and optimism [28][29] [30]. Agreeableness is defined as altruistic, tolerant, and trustworthy. This personality trait exhibited gullible, meek, and selfless behaviours and other prosocial behaviours [31][32][33]. Finally, Neuroticism is defined by the tendency to experience negative emotions exhibited through anxious, depressive, and insecure behaviours [34][35].

While previous research findings confirmed the relationship between personality traits and users' preferences, there is limited work that studies the association between personality traits and aesthetic dimensions. Most of the research studies focused on specific design features, neglecting the aesthetic dimensions. This research gap raises a question of whether personality traits affect user preference on aesthetic dimensions as it does with specific design features. Addressing this gap will present an opportunity to explore the predictive role of personality traits in determining which dimension of aesthetics has a strong influence on user preference. Therefore, this study was undertaken to fill the gap by analysing the correlation between the big-five personality traits and users' preferences over screenshots of web pages (homepage) representing classical and expressive aesthetics.

The rest of this paper is organized as follows. Section 2 discusses related works associated with the big-five personality traits and aesthetic preferences. Section 3 describes the methodology used in this study. Sections 4 and 5 present the finding and discussion, respectively. The conclusions are given in Section 6.

\section{RELATED WORK}

This section provides some references to previous work related to the big-five personality traits and aesthetic preferences.

According to [36], visual aesthetic sensitivity is independent of personality whilst others indicated that people high in Conscientiousness, Extraversion, and Agreeableness preferred common elements of design, such as the contrast between background and text, straightforward information display with the typical organisation of menu bar, scroll bar, and buttons [13][37][38]. These design elements are literally the execution of affordance and design convention. Affordance solicits users' actions without mental effort, whilst design convention influences users' expectations in the absence of affordance. Deviating from such intuition-centric would cause confusion and frustration for people high in Conscientiousness. People high in Conscientiousness further demonstrated positive inclinations toward conventional, clean, and orderly interface design features [39][40] and detest intense design style; complex and unconventional designs with irregular shapes of features [41].

Despite the fact that Openness to Experience has been widely examined, only a few empirical studies address its locus in design preference [12]. The author in [42] reported that people with high Openness to Experience tend to focus and adapt more inquisitively to an unconventional style of interface. Their preference for imaginative, untraditional, and personalised features allows them to quickly adapt to a new interface style. They relatively are not concerned with convention and are eager to explore new design features [43]. The consistent findings on unconventional design elements may explain the disposition towards expressive design in people with high Openness to Experience. However, unlike people high in Extraversion, people with high Openness to Experience are generally deterred by persuasive designs. Fear and stress are the reasons that discourage them from persuasive design [44].

Unlike Openness to Experience, which desires uniqueness, Extraversion desires extravagance, that is, the extreme continuum of design [45]. According to [46], Extraversion correlates with the desire for status, leading to a preference for extravagant designs. This is induced by the assertiveness trait in people high in Extraversion. People high in Extraversion prefer high colour contrasts, saturated hues, and bold or sharpedged shapes of the graphical interface [13][20]. Concerning utilisation of the adaptive interface, [47] revealed that the approach does not benefit Extraversion. In other words, people high in Extraversion do not respond well to monotonous interface set up by adaptation design.

On the other hand, people high in Agreeableness are relatively easy to accept any design presented to them [48]. They tend to be more receptive to design that generates a sense of certitude in relation to their personality traits defined by altruistic, tolerant, and trustworthiness. According to [49], Agreeableness is generally considered as an adaptive trait and correlates with the preference of authority figures. This is evident in a study to explore how personality features affect compliance towards recommendations, where they found that people high in Agreeableness follow the editor's suggestions. In other words, people high in Agreeableness cope with individuals who have reliable and verifiable qualities in related disciplines [50][51]. This might explain why they are easily more satisfied aesthetically compared to other traits [48]. Nevertheless, [52] revealed that people high in Agreeableness have a high preference for classical, representational art and less preference for abstract art.

Compared to the rest of the traits, Neuroticism is strongly associated with sensitive, obsessive, and anxious characters. Neurotic individuals exhibit an inclination towards asynchronous media as it enables higher situational control and avoids direct interactions with others [53][54]. They are concerned with the visual clarity and readability of interface design [13][15]. A study by [44] reported that people high in Neuroticism have a low preference toward designs that utilise persuasive strategies (i.e., competition, simulation, selfmonitoring and feedback, goal setting and suggestion, customisation, reward, social comparison, cooperation, punishment, and personalisation). These findings imply that people high in Neuroticism respond poorly to unconventional design features. Considering the immense magnitude of paranoia embedded in these individuals, it is very unlikely that they will advocate for expressive aesthetics. 
In general, the five personality traits of the big-five; Openness to experience, Cautiousness, Extraversion, Agreeableness, and Neuroticism, have unique characteristics that can influence their preferences towards classical or expressive aesthetics of interface design. Both Openness to experience and Extraversion individuals have shown noveltyseeking behaviour that corresponds to unconventional design, seemingly reflecting preference over expressive aesthetics. On the contrary, Conscientiousness and Neuroticism individuals have exhibited non-receptive behaviour towards novel-centric design concurrently with a positive response to design convention. These inclinations are apparently in agreement with an exposition of classical aesthetics. In comparison to other personality traits, Agreeableness individuals inhabit disparate behaviour that is highly flexible to both conventional and non-conventional design. The absence of preference over particular design categories implicates that Agreeableness individuals are receptive to both classical and expressive aesthetics.

The unique characteristics of each personality trait and their preference for specific design features, as discussed above, are useful to predict aesthetic dimensions. However, empirical evidence to support the accuracy of the prediction has been lacking. This study aims to provide an empirical evidence to confirm the predictive role of personality traits in predicting preference for aesthetic dimensions.

\section{METHOD}

The study consisted of two phases. Phase 1 was designed to classify website homepages into classical and expressive aesthetics. The selected web pages in phase 1 were used as stimuli in phase 2 to examine the relationship between aesthetic preferences and personality traits.

\section{A. Phase 1}

1) Participants: 128 undergraduate students of Universiti Malaysia Sabah voluntarily participated in the study. Of the 128 students, $98(77 \%)$ were students of the Faculty of Computing and Informatics, and 30 (23\%) were students of the Faculty of International Business and Finance. 86 (67\%) of the participants were female, and 42 (33\%) were male, with ages ranging from 19 to 26 years (Mean=22.69, SD=1.515). 46 (36\%) participants identified themselves as Chinese, 34 (27\%) as Native Borneo, 31 (24\%) as Malay, $16(12 \%)$ as Indian, and one (1\%) as others. The majority of the participants (65 (51\%)) spent more than 8 hours per day on computer/ internet, while 43 (34\%) spent 5-8 hours per day, 17 (13\%) spent 2-5 hours per day, and the remaining 3 (2\%) spent less than two hours per day.

2) Instrument: An online questionnaire administered via Google form and advertised through Facebook group pages and WhatsApp served as the main instrument of the experiment in phase 1 . The questionnaire was composed of three sections. Section 1 consisted of the consent form and instruction of the experiment. Section 2 was the demographic questions on age, gender, ethnicity, faculty, and duration of computer or internet use per day. Section 3 begins with definitions of classical and expressive aesthetics, followed by
30 screenshots of web pages, each accompanied by a 7-point Likert scale (1, classical aesthetics; 7, expressive aesthetics). The 30 screenshots were arranged vertically, one above another and presented in a different random order for each participant to avoid the order effect.

3) Task and procedure: The participants were required to complete all three sections of the questionnaire, starting from Sections 1 to 3. In Section 1, the participants were required to read the instruction and give their consent to participate. If the participants consented, they can click on the "Next" button to proceed to the next section. Otherwise, they can click on a "Cancel" button to withdraw from the experiment. In Section 2, the participants were required to answer five demographic questions related to age, gender, ethnicity, faculty, and the duration of computer/internet use per day. Upon completing Section 2, the participants proceeded to Section 3 by clicking the "Next" button. In Section 3, the participants were required to rate their perceived aesthetic dimension on each of the 30 screenshots of web pages on a 7point Likert scale (1-classical aesthetics, 7-expressive aesthetics). A definition of classical and expressive aesthetics was provided to ensure that all participants understood the term and rated the screenshots based on the same definition. The experiment ended when the participants click the "Submit" button.

4) Measure: The ratings of each web page were summed and ordered from lowest to highest score. Five web pages with the lowest scores and five with the highest scores were selected, and the remaining 20 were discarded to create a proper gap between the lowest and the highest. The five web pages with the lowest scores and five with the highest scores were classified as classical and expressive aesthetics, respectively, and used as stimuli in phase 2 .

\section{B. Phase 2}

1) Participants: A total of 220 undergraduate students of Universiti Malaysia Sabah voluntarily participated in the study. 153 of the total participants were students of the Faculty of Computing and Informatics, and 67 were International Business and Finance students. In terms of gender distribution, $70 \%$ (146) were females, and 30\% (71) were males with ages ranging from 20 to 27 (Mean=22.43, $\mathrm{SD}=1.41$ ). Ethnicity wise, $41 \%$ (91) participants identified themselves as Native Borneo, 30\% (66) as Chinese, 20\% (44) as Malay, $7 \%$ (16) as Indian, and 1\% (3) as others. In terms the duration of computer/ internet use per day, 53\% (116) of the participants reported that they spent more than 8 hours a day, 23\% (50) spent $5-8$ hours, 16\% (36) spent $3-5$ hours, $7 \%$ (16) spent 2 - 3 hours, and 1\% (2) spent less than an hour.

2) Instrument: An online questionnaire administered via Google form and advertised through Facebook group pages and WhatsApp served as the main instrument of this study. The questionnaire was composed of four sections. At the bottom page of Sections 1, 2 and 3, there was a "Next" button to move to the next section, whereas in Section 4, there was a 
"Submit" button to finish the questionnaire. The first two sections were identical to the first two sections in phase 1 . The third section consisted of 10 items of the Big Five Inventory (BFI-10) [51] (Table I). Each item of the BFI-10 was accompanied by a 5-point scale ranging from 1 (disagree strongly) to 5 (agree strongly).

TABLE I. BFI-10 [55]

\begin{tabular}{|l|l|l|l|l|l|}
\hline $\begin{array}{l}\text { I see myself as } \\
\text { someone who ... }\end{array}$ & $\begin{array}{l}\text { Disagree } \\
\text { strongly }\end{array}$ & $\begin{array}{l}\text { Disagree } \\
\text { a little }\end{array}$ & $\begin{array}{l}\text { Neither } \\
\text { disagree } \\
\text { or agree }\end{array}$ & $\begin{array}{l}\text { Agree } \\
\text { a } \\
\text { little }\end{array}$ & $\begin{array}{l}\text { Agree } \\
\text { strongly }\end{array}$ \\
\hline 1)... is reserved & 1 & 2 & 3 & 4 & 5 \\
\hline $\begin{array}{l}\text { 2)... is generally } \\
\text { trusting }\end{array}$ & 1 & 2 & 3 & 4 & 5 \\
\hline 3)... tends to be lazy & 1 & 2 & 3 & 4 & 5 \\
\hline $\begin{array}{l}4) \ldots \text { is relaxed, } \\
\text { handles stress well }\end{array}$ & 1 & 2 & 3 & 4 & 5 \\
\hline $\begin{array}{l}\text { 5)... has few artistic } \\
\text { interests }\end{array}$ & 1 & 2 & 3 & 4 & 5 \\
\hline $\begin{array}{l}\text { 6)... is outgoing, } \\
\text { sociable }\end{array}$ & 1 & 2 & 3 & 4 & 5 \\
\hline $\begin{array}{l}7) \ldots \text { tends to find } \\
\text { fault with others }\end{array}$ & 1 & 2 & 3 & 4 & 5 \\
\hline $\begin{array}{l}\text { 8)... does a thorough } \\
\text { job }\end{array}$ & 1 & 2 & 3 & 4 & 5 \\
\hline $\begin{array}{l}9) \ldots \text { gets nervous } \\
\text { easily }\end{array}$ & 1 & 2 & 3 & 4 & 5 \\
\hline $\begin{array}{l}\text { 10)... has an active } \\
\text { imagination }\end{array}$ & 1 & 2 & 3 & 4 & 5 \\
\hline
\end{tabular}

The fourth section contained 10 screenshots of web pages (see Appendix) derived from phase 1, five screenshots each for classical and expressive aesthetics. Each screenshot was presented with a 7-point Likert scale, anchored by 1 (I don't like it) and 7 (I like it a lot). The ten screenshots were arranged vertically, one above another and presented in a different random order for each participant to avoid the order effect.

3) Task and procedure: The participants were required to complete all four sections of the questionnaire, starting from Sections 1 to 4. Upon completing Section 1, the participants can move to the next section by clicking on the "Next" button. This process continued until all sections were completed. The experiment ended when the participants clicked on the "submit" button in Section 4.

The task and procedure of sections 1 and 2 were similar to that of Sections 1 and 2 in phase 1 . In Section 3, the participants were asked to answer all 10 items of BFI-10 by giving a rating from 1 (disagree strongly) to 5 (agree strongly) to each item. In Section 4, the participants were asked to indicate the extent of their preference from 1 (I don't like it) to 7 (I like it a lot) for each of the 10 screenshots of web pages.

4) Measures: Personality traits were measured using BFI10 [55]. BFI-10 is a shorter version of the well-established BFI-44 [56]. Compared to BFI-44, which consisted of 44 items with 8 to 10 items per trait, BFI-10 consisted of only 10 items with two items per trait (Table I). Although short, this shorter version of BFI-44 claimed to predict almost $70 \%$ of the variance of the scales [57]. Each item of BFI-10 was rated from 1 (disagree strongly) to 5 (agree strongly). Scale score was obtained by the average rating of 2 items where 1 item was reversed-scored (Extraversion: 1R, 6; Agreeableness: 2, 7R; Conscientiousness: 3R, 8; Neuroticism: 4R, 9; Openness to experience: $5 \mathrm{R}, 10, \mathrm{R}=\mathrm{item}$ is reversed-scored). The internal consistency reliability of the scales was not reported in this study. A small number of items always yielded inadequate internal consistency reliability; thus, internal consistency is not an adequate measure for BFI-10 [58]. Preference for classical and expressive aesthetics was measured using a 7-point Likert scale; 1 reflects the least preference, and 7 reflects the greatest preference. Fig. 1 shows the hypothetical model of this study.

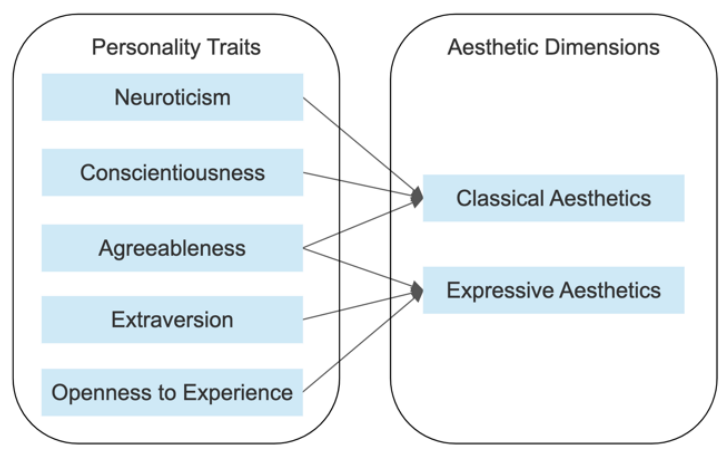

Fig. 1. Hypothetical Path Model.

\section{RESULT}

This study used SPSS (version 26) for Windows to perform the statistical analysis of the questionnaire data. The statistical analysis used, including Pearson's correlation and multiple regression analysis with the stepwise method, to identify a possible association between aesthetic preferences and personality traits. Table II shows the overall results of this study.

TABLE II. CORRELATION MATRIX

\begin{tabular}{|c|c|c|c|c|c|c|}
\hline \multirow{2}{*}{$\begin{array}{l}\text { Personality } \\
\text { / Dimension }\end{array}$} & \multirow{2}{*}{$\mu$} & \multirow{2}{*}{$\sigma$} & \multicolumn{2}{|c|}{$\begin{array}{l}\text { Classical } \\
\text { aesthetics }\end{array}$} & \multicolumn{2}{|c|}{$\begin{array}{l}\text { Expressive } \\
\text { aesthetics }\end{array}$} \\
\hline & & & $r$ & $\alpha$ & $r$ & $\alpha$ \\
\hline $\mathrm{O}$ & 3.1000 & .5564 & -.029 & .664 & -.118 & .081 \\
\hline C & 3.0068 & .7207 & -.010 & .883 & .075 & .265 \\
\hline $\mathrm{E}$ & 2.8250 & 6908 & -.041 & .549 & .075 & .271 \\
\hline A & 3.5614 & .7132 & $.161 *$ & .017 & $.133^{*}$ & .049 \\
\hline $\mathrm{N}$ & 3.1318 & .8335 & -.042 & .537 & -.056 & .407 \\
\hline $\begin{array}{l}\text { Classical } \\
\text { aesthetics }\end{array}$ & 3.9291 & 1.0128 & & & & \\
\hline $\begin{array}{l}\text { Expressive } \\
\text { aesthetics }\end{array}$ & 5.2327 & .7938 & & & & \\
\hline
\end{tabular}

The result of the Pearson product-moment correlation showed that Agreeableness was significantly correlated, albeit weak, with classical aesthetics $(r=.161, \mathrm{p}=.017, \mathrm{n}=220)$ and expressive aesthetics $(r=.133, \mathrm{p}=.049, \mathrm{n}=220)$ (Fig. 2). The 
strength of correlation of Agreeableness on classical aesthetics was slightly higher than on expressive aesthetics; but clearly the numbers are too small to make the differences meaningful. Other personality traits (i.e., Openness to Experience, Conscientiousness, Extraversion, Neuroticism), however, were found not significantly correlated with either classical or expressive aesthetics (Fig. 2).

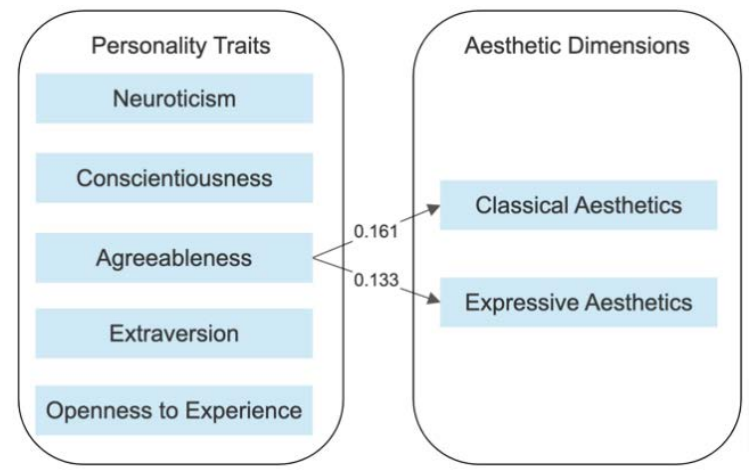

Fig. 2. Data-driven Path Model.

The result of a series of stepwise linear regression analyses with preferences as criteria showed that Agreeableness was the only personality trait that survived the stepwise procedure for classical and expressive aesthetics. For classical aesthetics, a significant regression equation was found $(F(1,218)=$ 5.794, $\mathrm{p}<0.05$ ) with an $\mathrm{R}^{2}$ of .026 . Participants' predicted classical aesthetics is equal to $3.115+.228$ (Agreeableness) when Agreeableness is measured on a Likert scale. Classical aesthetics increased .228 for each point of Agreeableness. For expressive aesthetics, a significant regression equation was found $(\mathrm{F}(1,218)=3.909, \mathrm{p}<0.05)$ with an $\mathrm{R}^{2}$ of .018 . Participants' predicted expressive aesthetics is equal to 4.707 +.148 (Agreeableness) when Agreeableness is measured on a Likert scale. Expressive aesthetics increased .148 for each point of Agreeableness.

The personality traits' contribution to being able to predict preferences for aesthetics of different dimensions was relatively low, with all predictors together accounting for only $2.8 \%$ of the variance for the classical aesthetics and $4.2 \%$ of the variance for the expressive aesthetics. As in the case of aesthetic preference, Agreeableness was shown as the most important characteristic of the big-five personality traits. Agreeableness was predictive of classical and expressive aesthetics whereas the others were not.

\section{DISCUSSION}

The study demonstrates that among the big-five personality traits, Agreeableness was the only trait that significantly, albeit weakly, correlated with classical and expressive aesthetics. A closer look at the correlation of Agreeableness on classical and expressive aesthetics revealed that the strength of correlation between Agreeableness and classical aesthetics $(r=.161)$ was slightly higher than between Agreeableness and expressive aesthetics $(r=.133)$. This result can be interpreted in two ways. First, people with Agreeableness prefer classical aesthetics over expressive aesthetics. This interpretation is in line with [52], who conducted a study in visual art and found that people with
Agreeableness prefer representational arts over abstract arts. Second, people with Agreeableness prefer both classical and expressive aesthetics. This interpretation is based on the trivial difference in the correlation coefficient between classical and expressive aesthetics (i.e., 0.028) and is aligned with our hypothesis that people with Agreeableness are receptive to any form of aesthetics presented to them.

Conversely, the absence of a significant correlation of Openness to Experience, Conscientiousness, Extraversion, and Neuroticism on both classical and expressive aesthetics implies that these four personality traits have no influence over user preference on aesthetic dimensions. This finding correlated well with [36], who claimed that visual aesthetic sensitivity was independent of personality. Our work extends their study by employing a website interface with all adult subjects (21-27 years) in comparison to using artwork as stimuli with mostly children (10-15 years) in assessing the independence of visual aesthetic sensitivity from personality traits. This finding adds to the literature suggesting that aesthetic preference is independent from personality across computer or non-computer interface and age groups (i.e. children and young adults).

Apart from the immediate results, the findings of this study should also be considered within the context of its limitations. As in most empirical studies, the study conducted here was limited by the measure used to examine user preferences. Since user preferences were measured using static screenshots of web pages, the results may only apply to non-interactive interfaces, whereas the use of interactive interfaces as stimuli may potentially alter the results. This is an interesting aspect to be carried out in prospective work.

In addition, the subjects in this study were undergraduate university students. This restricted sample of subjects may hinder the generalizability of the findings across the populations. The opportunity to evaluate other populations may provide insight into interpopulation perspectives of user preference. Replicating findings in different contexts and with different populations may possibly benefit the knowledgebuilding process, theoretical refinement, and applicability in other situations [59][60].

\section{CONCLUSION}

This study examined the relationship between personality traits and aesthetic dimensions. The results showed a weak relationship between personality traits and aesthetic dimensions, thus suggesting that personality traits are not a good predictor of aesthetic dimension preferences. Previous literature and our findings collectively illuminate the fact that personality measures appeared more useful in predicting aesthetic preference of individual design features than the aesthetic dimension of interface. In the future, other than using different stimuli and populations, further study should consider inductive research design to gain a qualitative understanding of underlying reasons and motivations for aesthetic preferences.

\section{REFERENCES}

[1] Shirole, A. Chowdhury, and D. Dhar, "Identification of Aesthetically Favourable Interface Attributes for Better User Experience of Social 
Networking Application,” in Ergonomics in Caring for People, Springer, 2018, pp. 251-259.

[2] M. Simões-Marques, A. Correia, M. F. Teodoro, and I. L. Nunes, "Empirical studies in user experience of an emergency management system," in International Conference on Applied Human Factors and Ergonomics, 2017, pp. 97-108.

[3] S. L. T. Hui and S. L. See, "Enhancing user experience through customisation of UI design,” Procedia Manuf., vol. 3, pp. 1932-1937, 2015.

[4] S. Liu, T. Liang, S. Shao, and J. Kong, "Evaluating localized MOOCs: The role of culture on interface design and user experience," IEEE Access, vol. 8, pp. 107927-107940, 2020.

[5] S. Lee and R. J. Koubek, "Understanding user preferences based on usability and aesthetics before and after actual use," Interact. Comput., vol. 22, no. 6, pp. 530-543, 2010.

[6] D. A. Norman, "Emotion \& design: attractive things work better," interactions, vol. 9, no. 4, pp. 36-42, 2002.

[7] T. Lavie and N. Tractinsky, "Assessing dimensions of perceived visual aesthetics of web sites,” Int. J. Hum. Comput. Stud., vol. 60, no. 3, pp. 269-298, 2004.

[8] J. Nielsen and K. Pernice, Eyetracking web usability. New Riders, 2010.

[9] G. Lindgaard, G. Fernandes, C. Dudek, and J. Brown, "Attention web designers: You have 50 milliseconds to make a good first impression!," Behav. Inf. Technol., vol. 25, no. 2, pp. 115-126, 2006.

[10] N. Tractinsky, A. Cokhavi, M. Kirschenbaum, and T. Sharfi, "Evaluating the consistency of immediate aesthetic perceptions of web pages,” Int. J. Hum. Comput. Stud., vol. 64, no. 11, pp. 1071-1083, 2006.

[11] C. H. Wood and C. P. Keller, Cartographic design: Theoretical and practical perspectives. Wiley Chichester, UK, 1996.

[12] T. Alves, J. Natálio, J. Henriques-Calado, and S. Gama, "Incorporating personality in user interface design: A review,” Pers. Individ. Dif., vol. 155, p. 109709, 2020.

[13] S. M. Sarsam and H. Al-Samarraie, "Towards incorporating personality into the design of an interface: a method for facilitating users' interaction with the display," User Model. User-adapt. Interact., vol. 28, no. 1, pp. 75-96, 2018.

[14] R. Aktivia, T. Djatna, and Y. Nurhadryani, "Visual usability design for mobile application based on user personality," in 2014 International Conference on Advanced Computer Science and Information System, 2014, pp. 177-182.

[15] L. Arockiam and J. C. Selvaraj, "User interface design for effective elearning based on personality traits,” Int. J. Comput. Appl., vol. 61, no. 14, 2013.

[16] J. Kim, A. Lee, and H. Ryu, "Personality and its effects on learning performance: Design guidelines for an adaptive e-learning system based on a user model,” Int. J. Ind. Ergon., vol. 43, no. 5, pp. 450-461, 2013.

[17] A. D. Shaikh, B. S. Chaparro, and D. Fox, "Perception of fonts: Perceived personality traits and uses," Usability news, vol. 8, no. 1, pp. 1-6, 2006.

[18] B. Saati, M. Salem, and W.-P. Brinkman, "Towards customized user interface skins: investigating user personality and skin colour," Proc. HCI 2005, vol. 2, pp. 89-93, 2005.

[19] E. Abrahamian, J. Weinberg, M. Grady, and C. M. Stanton, "The effect of personality-aware computer-human interfaces on learning," J. Univers. Comput. Sci., vol. 10, no. 1, pp. 27-37, 2004.

[20] A. Karsvall, "Personality preferences in graphical interface design," in ACM International Conference Proceeding Series, 2002, vol. 31, pp. 217-218, doi: 10.1145/572020.572049.

[21] L. R. Goldberg, "An alternative" description of personality": the big-five factor structure.,” J. Pers. Soc. Psychol., vol. 59, no. 6, p. 1216, 1990.

[22] P. J. Silvia and A. P. Christensen, "Looking up at the curious personality: Individual differences in curiosity and Openness to Experience,” Curr. Opin. Behav. Sci., vol. 35, pp. 1-6, 2020.

[23] M. Ahmad and Z. Maochun, "Personality traits and investor decisions," Asian J. Econ. Financ. Manag., pp. 19-34, 2019.
[24] R. R. McCrae and P. T. Costa Jr, “Openness to experience,” Perspect. Personal., vol. 1, pp. 145-172, 1985.

[25] L. Zhang and H. Liu, "Effects of Conscientiousness on Users' EyeMovement Behaviour with Recommender Interfaces,” in International Conference on Human-Computer Interaction, 2019, pp. 367-376.

[26] U. J. Wiersma and R. Kappe, "Selecting for extroversion but rewarding for conscientiousness,” Eur. J. Work Organ. Psychol., vol. 26, no. 2, pp. 314-323, 2017.

[27] H. S. Friedman and M. L. Kern, "Personality, well-being, and health," Annu. Rev. Psychol., vol. 65, pp. 719-742, 2014.

[28] A. Spark and P. J. O'Connor, “State extraversion and emergent leadership: Do introverts emerge as leaders when they act like extraverts?,” Leadersh. Q., vol. 32, no. 3, p. 101474, 2021.

[29] L. Terrier, S. Kim, and S. Fernandez, "Who are the good organizational citizens for the environment? An examination of the predictive validity of personality traits,” J. Environ. Psychol., vol. 48, pp. 185-190, 2016.

[30] R. R. McCrae and P. T. Costa Jr, "Discriminant validity of NEO-PIR facet scales,” Educ. Psychol. Meas., vol. 52, no. 1, pp. 229-237, 1992.

[31] M. T. Argan and M. Argan, "Do altruistic values of an individual reflect personality traits,” Int. J. Recent Adv. Organ. Behav. Decis. Sci. An Online Int. Res. J., vol. 3, no. 1, pp. 858-871, 2017.

[32] B. Osatuyi, "Personality traits and information privacy concern on social media platforms," J. Comput. Inf. Syst., vol. 55, no. 4, pp. 11-19, 2015.

[33] N. Capuano, G. D’Aniello, A. Gaeta, and S. Miranda, "A personality based adaptive approach for information systems," Comput. Human Behav., vol. 44, pp. 156-165, 2015.

[34] S. Sauer-Zavala, J. G. Wilner, and D. H. Barlow, "Addressing neuroticism in psychological treatment.," Personal. Disord. Theory, Res. Treat., vol. 8, no. 3, p. 191, 2017.

[35] C. Arslan, "Interpersonal problem solving, self-compassion and personality traits in university students,” Educ. Res. Rev., vol. 11, no. 7, pp. 474-481, 2016.

[36] J. P. Fróis and H. J. Eysenck, "The Visual Aesthetic Sensitivity Test applied to Portuguese children and fine arts students," Creat. Res. J., vol. 8, no. 3, pp. 277-284, 1995.

[37] C. M. R. Leung, "Human factors in website usability and aesthetics: theory and applications to hotels in Hong Kong," 2013.

[38] R. Leung, J. Rong, G. Li, and R. Law, "An analysis on human personality and hotel web design: A Kohonen network approach," in ENTER, 2011, pp. 573-585.

[39] J. Zhang, Y. Luximon, and Y. Song, “The role of consumers' perceived security, perceived control, interface design features, and conscientiousness in continuous use of mobile payment services," Sustainability, vol. 11, no. 23, p. 6843, 2019.

[40] E. Geisler-Brenstein and R. R. Schmeck, "The revised inventory of learning processes: A multifaceted perspective on individual differences in learning," in Alternatives in assessment of achievements, learning processes and prior knowledge, Springer, 1996, pp. 283-317.

[41] K. Cleridou and A. Furnham, "Personality correlates of aesthetic preferences for art, architecture, and music," Empir. Stud. Arts, vol. 32, no. 2, pp. 231-255, 2014.

[42] R. G. Saadé, D. Kira, F. Nebebe, and C. Otrakji, "Openness to Experience: An HCI Experiment.,” Issues informing Sci. Inf. Technol., vol. 3, 2006.

[43] P. Kortum and F. L. Oswald, "The impact of personality on the subjective assessment of usability,” Int. J. Human-Computer Interact., vol. 34, no. 2, pp. 177-186, 2018.

[44] R. Orji, L. E. Nacke, and C. Di Marco, "Towards personality-driven persuasive health games and gamified systems," in Proceedings of the 2017 CHI Conference on Human Factors in Computing Systems, 2017, pp. 1015-1027.

[45] D. R. Dunaetz, T. C. Lisk, and M. M. Shin, "Personality, gender, and age as predictors of media richness preference," Adv. Multimed., vol. 2015, 2015.

[46] D. Greenberg, E. Ehrensperger, M. Schulte-Mecklenbeck, W. D. Hoyer, Z. J. Zhang, and H. Krohmer, "The role of brand prominence and extravagance of product design in luxury brand building: What drives 
consumers’ preferences for loud versus quiet luxury?,” J. Brand Manag., vol. 27, no. 2, pp. 195-210, 2020.

[47] K. Z. Gajos and K. Chauncey, "The influence of personality traits and cognitive load on the use of adaptive user interfaces," in Proceedings of the 22nd International Conference on Intelligent User Interfaces, 2017, pp. 301-306.

[48] K. Oyibo, R. Orji, and J. Vassileva, "The influence of personality on mobile web credibility," in Adjunct Publication of the 25th Conference on User Modeling, Adaptation and Personalization, 2017, pp. 53-58.

[49] P. Unal, T. T. Temizel, and P. E. Eren, "What installed mobile applications tell about their owners and how they affect users' download behavior,” Telemat. Informatics, vol. 34, no. 7, pp. 1153-1165, 2017.

[50] N. S. A. Karim, N. H. A. Zamzuri, and Y. M. Nor, "Exploring the relationship between Internet ethics in university students and the big five model of personality,” Comput. Educ., vol. 53, no. 1, pp. 86-93, 2009.

[51] H. Zhao and S. E. Seibert, "The big five personality dimensions and entrepreneurial status: A meta-analytical review.,” J. Appl. Psychol., vol. 91, no. 2, p. 259, 2006.

[52] A. Furnham and M. Avison, "Personality and preference for surreal paintings,” Pers. Individ. Dif., vol. 23, no. 6, pp. 923-935, 1997.

[53] R. Leung, J. Rong, G. Li, and R. Law, "Personality differences and hotel web design study using targeted positive and negative association rule mining,” J. Hosp. Mark. Manag., vol. 22, no. 7, pp. 701-727, 2013.
[54] G. Hertel, J. Schroer, B. Batinic, and S. Naumann, "Do shy people prefer to send e-mail? Personality effects on communication media preferences in threatening and nonthreatening situations," Soc. Psychol. (Gott)., vol. 39, no. 4, pp. 231-243, 2008.

[55] B. Rammstedt and O. P. John, "Measuring personality in one minute or less: A 10-item short version of the Big Five Inventory in English and German,” J. Res. Pers., vol. 41, no. 1, pp. 203-212, 2007.

[56] O. P. John, E. M. Donahue, and R. L. Kentle, "Big five inventory,” J. Pers. Soc. Psychol., 1991.

[57] B. A. Balgiu, "The psychometric properties of the Big Five inventory-10 (BFI-10) including correlations with subjective and psychological wellbeing,” Glob. J. Psychol. Res. New Trends Issues, vol. 8, no. 2, pp. 6169, 2018.

[58] B. Spinath, H. H. Freudenthaler, and A. C. Neubauer, "Domain-specific school achievement in boys and girls as predicted by intelligence, personality and motivation,” Pers. Individ. Dif., vol. 48, no. 4, pp. 481486, 2010.

[59] C. J. Coulton, "The need for replication in social work research," in Social Work Research and Abstracts, 1982, vol. 18, no. 2, p. 2.

[60] R. A. Bettis, C. E. Helfat, and J. M. Shaver, "The necessity, logic, and forms of replication,” Strateg. Manag. J., vol. 37, no. 11, pp. 2193-2203, 2016.

\section{ApPendiX: SAMPLE OF Web Pages THAT WeRE USED IN THE STUdY}

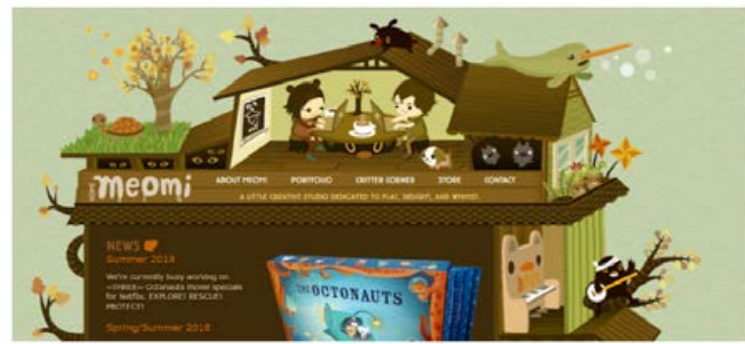

Source: http://www.meomi.com

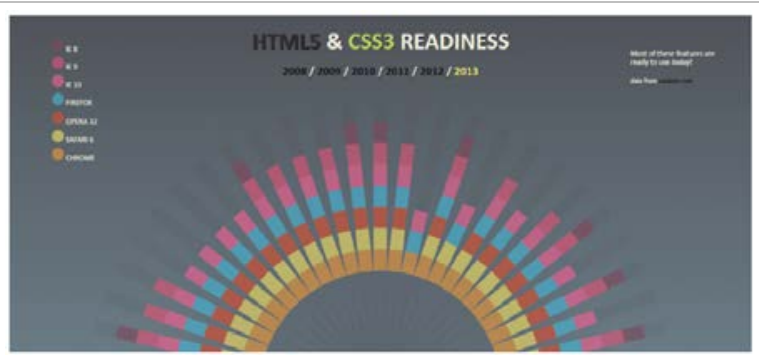

Source: https://html5readiness.com

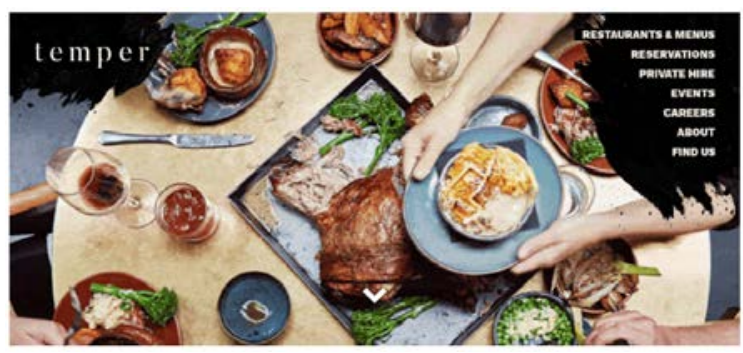

Source: https://temperrestaurant.com
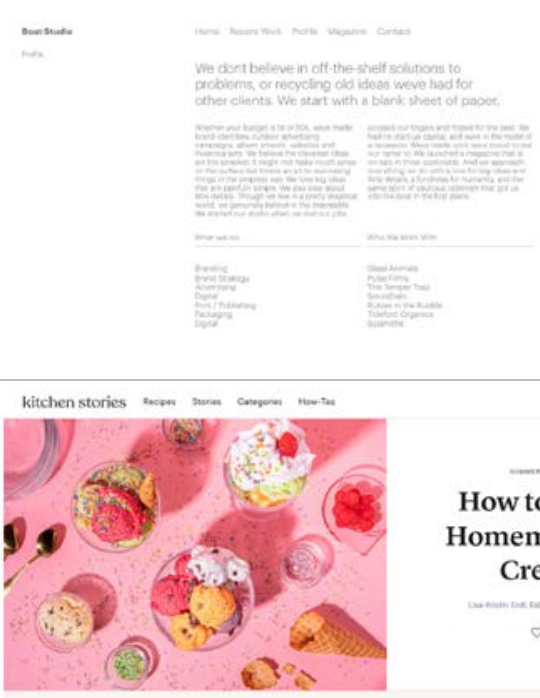

How to Make

Homemade Ice Cream

Source: https://www.kitchenstories.com

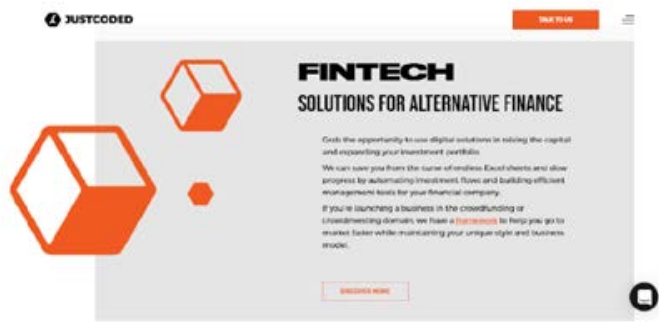

Source: https://justcoded.com 


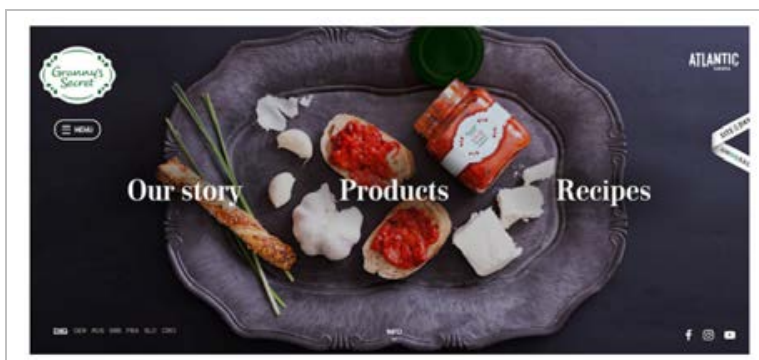

Source: https://www.grannyssecret.com/

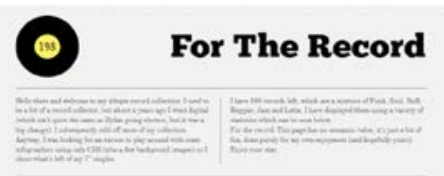

(3)

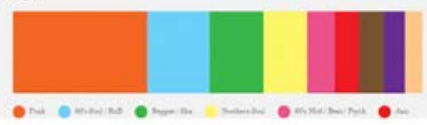

Source: http://www.fortherecord.simonfosterdesign.com/

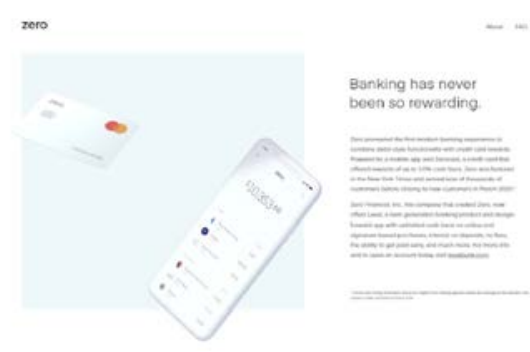

Source: https://www.webdesignersacademy.com/inspiration/zero-app/

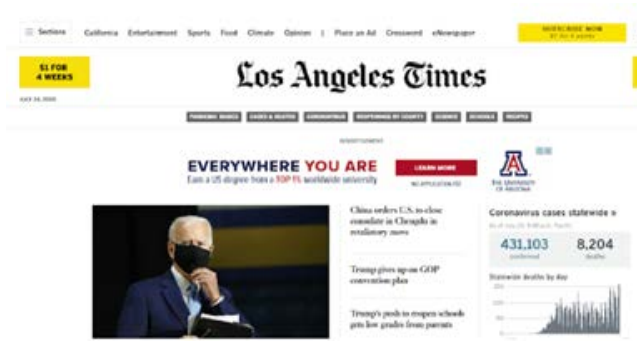

Source: https://www.latimes.com 